\title{
Hands to Work, Hearts to God: The Story of the Shaker Seed Industry
}

\author{
Laura Paine
}

Summary. The Shakers were a celibate, communistic religious group, active primarily in the 18th and 19th centuries in the United States. Well-known for their craftsmanship in making furniture and other household items, their expertise extended far beyond these areas into a broad range of industries, including many agricultural enterprises. Seeds of vegetable varieties were produced and marketed independently by several of the Shaker communities starting in the late 18th century. During the first part of the 19th century, Shaker peddlers were one of a very few sources of vegetable seed for American gardeners, and seed sales comprised a major portion of the Shaker communities' income. Shaker doctrine encouraged excellence and integrity in all their business practices. These characteristics were largely responsible for the Shakers' success in the seed industry, as well as for their ultimate decline. Their enterprise sprang from their rural, agricultural roots and their markets were the small villages and farming communities across the eastern United States. The Shaker seed industry thus developed independent of the market forces governing "the World." The commercial seed industry, based in Philadelphia (beginning in the first decades of the 1800s), and the Shaker seed industry had little effect on one another until mid-century, when improved transportation and mail service opened rural markets to the mainly city-based commercial seed dealerships. Unwilling to compete with commercial dealers, the Shaker seed industry gradually declined until the turn of the century, when it ceased to exist.

"In the year 1790, Believers in this place had a Little Family garden occupying about two acres of land. Joseph Turner worked it and began to raise a few kinds of seeds to sell. Previous to this it was not customary in this part of the country for people to raise garden seeds for sale. When any neighbor lacked seeds, another would give him what he wanted and did not think of asking pay, more than they would for a bucket of water." (WRHS Collection, n.d.)

I $\mathrm{n}$ the late 1700s, gardeners of the Shaker colonies of Watervliet and New Lebanon, N.Y., began selling garden seeds to neighboring farmers. From this modest beginning sprang a seed production enterprise that eventually extended across eastern North America and spanned a century. The Shakers set a standard for quality and reliability for their seed industry in an era when such standards were rare in any business. Both their successes and their ultimate demise were the result of a unique spiritually oriented business ethic. Who were the Shakers and what was the influence of their faith on their seed enterprise?

Department of Agronomy, University of Wisconsin, Madison, WI 53706. 


\section{The Shakers}

The United Society of Believers in Christ's Second Appearing (the Shakers) was a communal Christian sect founded in England in the mid-18th century (Melcher, 1941). Their doctrine held that Jesus Christ would be manifested on earth in both male and female form. The Shakers' spiritual leader, Mother Ann Lee, was thought to be the female personification of God. In 1774, the small group, led by Ann Lee, emigrated to North America to escape persecution for their beliefs. They landed in New York City and, in 1787, settled the village of watervliet, near Albany, N.Y. Their beliefs mandated that they live communally, apart from society. Missionaries were sent out into "the Fig. 1. Map of eastern Unite States showing locations and dates of Shaker colonies.

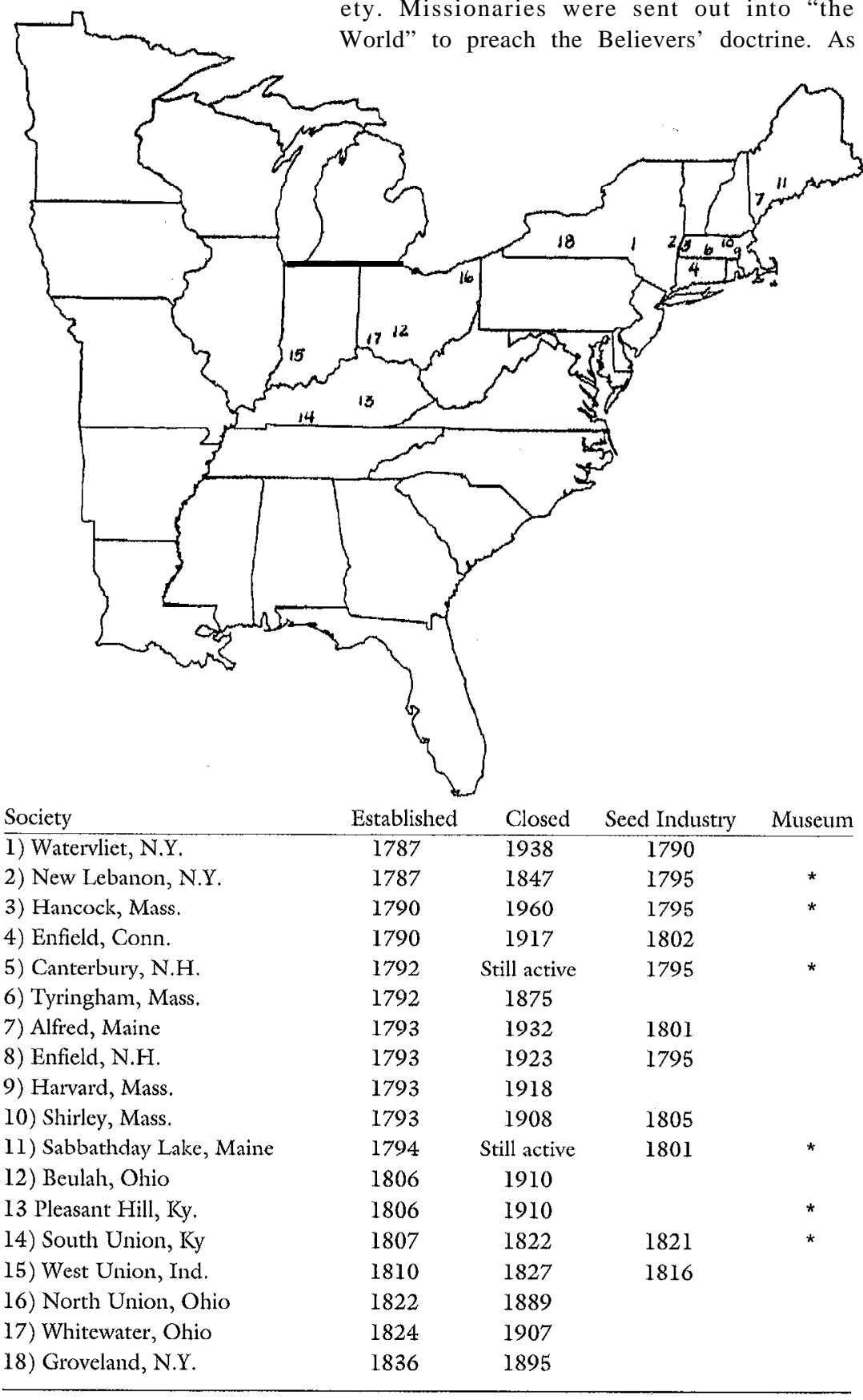

the sect gained converts in the following years, many more villages were founded across New England and as far west as Ohio and Kentucky (Fig. 1). Each was a self-governing unit, although the groups, or "families," as they called themselves, were united into regional Bishoprics and all answered to the Elders of the Shaker community of New Lebanon, N.Y. (Melcher, 1941).

Shaker communalism was an integral part of their spiritual life. They believed that their devotion to God was manifested through their work and social structure. The phrase "Hands to Work, Hearts to God," attributed to Mother Ann Lee, embodies the essence of their faith. Shaker doctrine called for them to devote themselves fully to the service of God. Marriage was not allowed among society members-the Shaker "family" did not arise from the union of two individuals, but from a common commitment among members to the service of God. The Shaker creed involved a commitment to the equality of the sexesmen and women shared equally in the leadership of each community as well as in the tasks required to provide for the family.

This religious creed was the foundation for the development of Shaker industries. The Shaker business principles that evolved from this creed are summarized by Andrews and Andrews (1974), as follows:

1) The recognition and use of native aptitudes and skills. Individuals were encouraged to develop skills in several trades.

2) Respect for "hand" labor and refusal to acknowledge any rank based on the value of certain types of work over others.

3) Recognition of the equality of the sexes-in responsibilities as well as rights.

4) The doctrine of perfectionism, the divinity of striving for excellence in every endeavor. This was an overriding goal in all of the Shakers industries.

5) Order, utility, and improvement guided their economy. All Shaker industries involved necessary products, made simply and without adornment,

6) "The right use of property." Private property was not allowed in Shaker society. Property belonged to God and should be used not to further man's personal ends, but to do the Lord's work in the world.

The Shakers spiritual devotion manifested itself in a strong work ethic and an unrivaled attention to detail in their daily activities. By striving for perfection, they believed that they were doing God's work. They farmed, raising most of their own meat, vegetables, and grain. They built well-crafted, unadorned houses for themselves and their livestock and complemented their plain designs with simple, elegant furniture and tools. They lived a spartan life-working hard; eat- 
ing simple, hearty meals; and emphasizing cleanliness and personal health. Work was an end in itself, a spiritual exercise and a sign of devotion to God.

A conscious effort was made by each society to produce salable items with the goal of supplying funds for purchase of those things that they needed but could not supply for themselves. Each Shaker society developed its industries based on the special skills and talents of its members: This is how the Shaker seed industry began. Because of their work ethic and the quality of their goods, the Shakers became well-known as fine craftsmen and producers ofhigh-quality products. During the first decades of the 19th century, Shaker seeds were widely considered the best available in North America (Hedrick, 1950; Pieters, 1900).

\section{The early seed industry}

At least two Shaker communities claimed to have been the first to produce seeds for sale. Joseph Turner of Watervliet, N.Y., recorded that he set aside the first acreage for seed raising in 1790 (Sommer, 1972). Gardeners at New Lebanon began selling their surplus seed in 1789 or 1790 , but did not set aside land for this purpose until 1795 (Sommer, 1972). By that year, the societies of Hancock, Canterbury, and Enfield, N.H., had joined the enterprise, as well. The New Lebanon community appears to have been one of the most successful overall-one of the longest-lived seed businesses and one of the most innovative. They came to refer to themselves in their advertisements as "The Shaker Seed Company."

Early offerings of seeds were limited, but, as sales increased, many varieties were added to the seed lists. New Lebanon records indicate that the best-selling seed in the late 1700 s to early 1800 s was onion. Seedsman Artemas Markham lists $201 \mathrm{lb}$ of onion seed produced and sold in 1795. Other vegetable varieties sold in that first year included scarcity beet (a fodder beet, also known as mangel-wurzel), carrot, cucumber, and summer squash. In that year, a combined total of $44 \mathrm{lb}$ of these varieties was sold, with an income listed at \$406 (Andrews and Andrews, 1974). The next year, records indicate that two varieties of turnip and three of cabbage were added to this list. By 1800, income from sales of seeds other than onion at New Lebanon had more than doubled to $\$ 1000$. A number of societies joined the early producers in the first years of the 19th century. By 1820, nearly all the Shaker societies were producing seed for sale. Records show that at least 16 of the 18 longlived societies had seed-production enterprises (Beale and Boswell, 1991; Sommer, 1972).

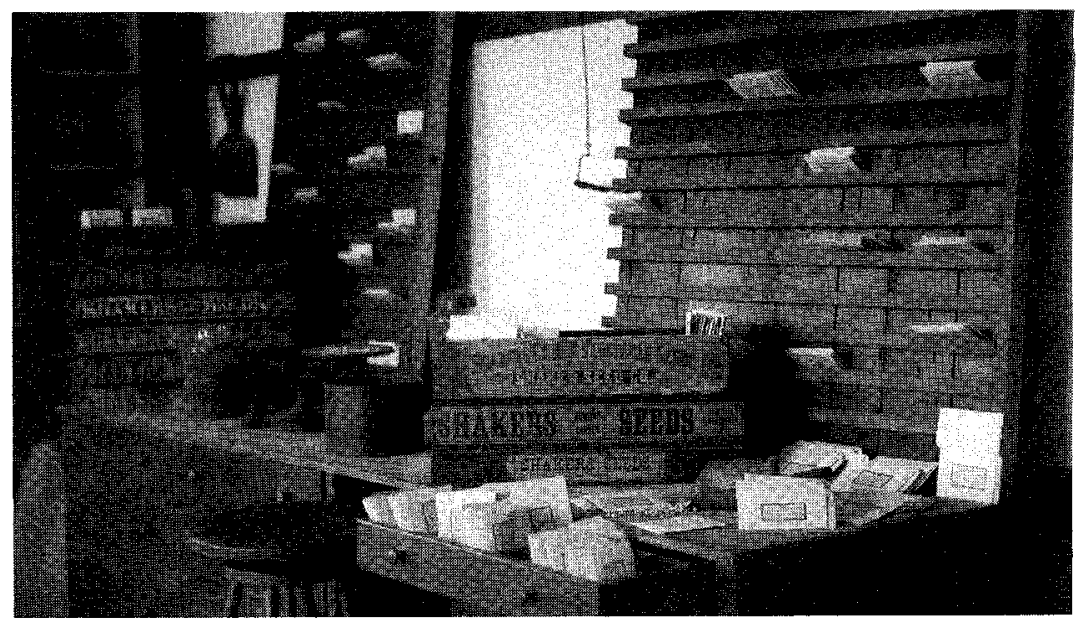

From the 1780 s until the mid-1800s, the Shakers were the only source of purchased seed available to rural Americans. Commercial dealers offered seed for sale in and around major cities on the East Coast, but poor transportation and mail service limited the availability of these sources to rural communities (Landreth, 1923). At first, nearly all commercial vegetable seed was imported from Europe, with later sources being market gar-

Fig. 2. The interior of a seed processing room at Pleasant Hill Shaker Village in Kentucky. Pleasant Hill is now operated as an open-air museum.

Fig 3. Garden seed sales lists from the Shirley, Mass.,

Shaker colony, 1826 (WRHS Collection).

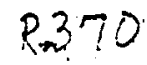
$59^{\circ}$

\section{No.b)}

\section{GARDEN SEEDS,}

Raised at Shirley, Hiassachusetts, and sold by 1826 orrving BURx,

AMONG WHICI ARE THE FOLLOWING:

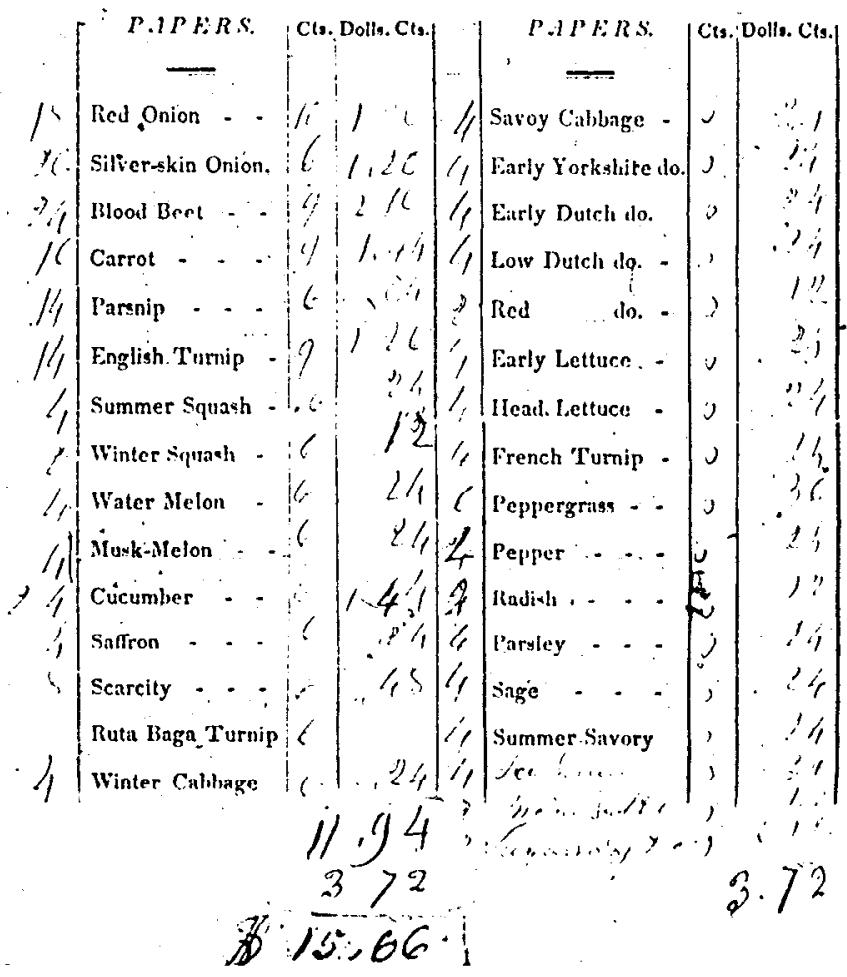




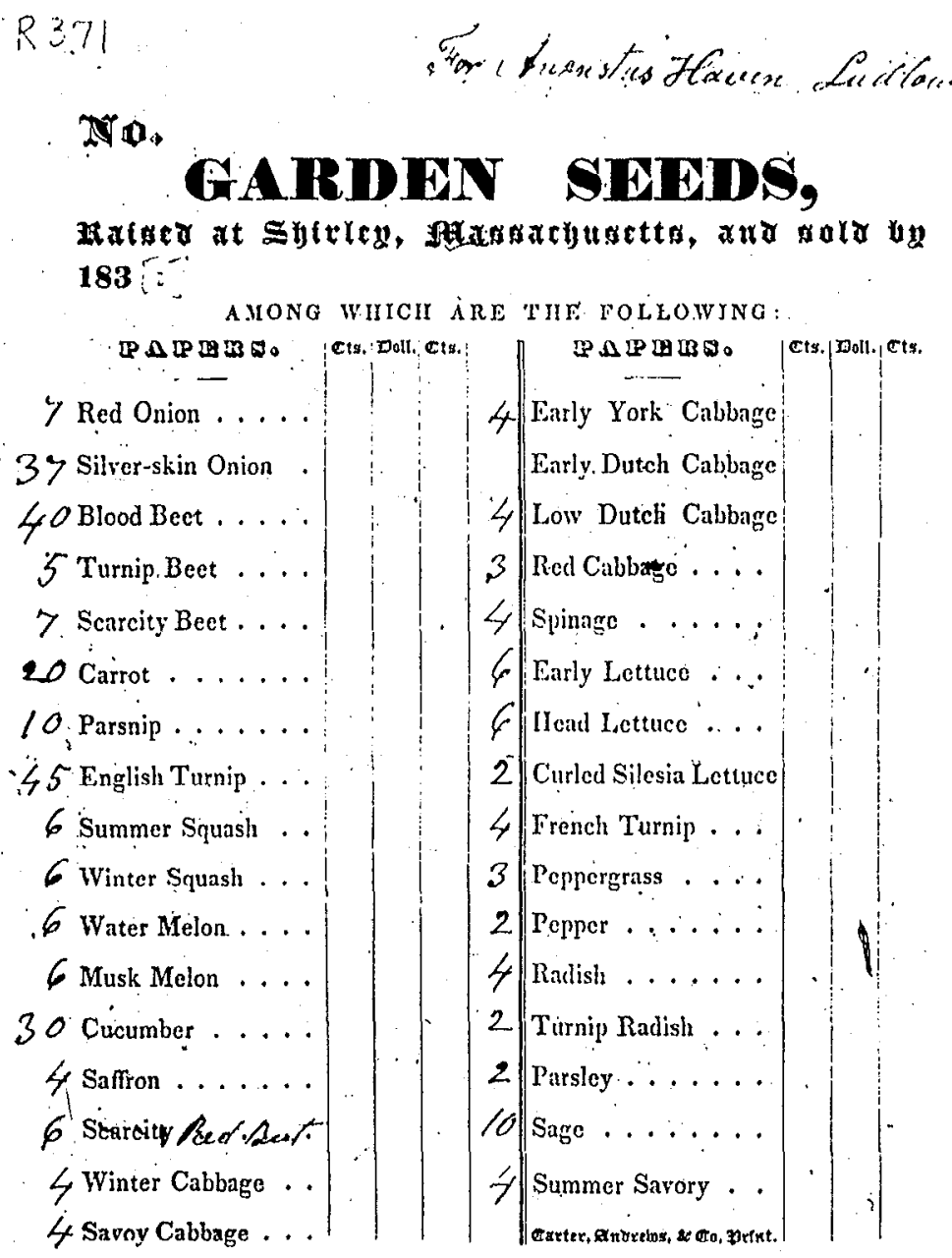

Fig. 4. Garden seed sales lists from the Stirley, Mass., Shaker colony, 1832 (WRHS Collection).

\section{The shakers are thought to bave developed the innovation of packaging seeds for sale in small paper packets."}

deners and contract growers. Only a few of the larger companies raised their own seed beginning in the mid-1800s (Hedrick, 1950). Most seed dealers operated this business as a sideline and many went into the business knowing little or nothing about seed or plants. One such early seed dealer was Grant Thorburn, who began selling vegetable seeds in his grocery store in Philadelphia in 1809. Quality of the seed was a major issue for these early dealers, as Thorburn describes in the following passage:

"Being a mechanic by profession and alike ignorant of seeds and gardening, I had land to struggle with the impositions of unprincipled seed raisers, they often selling me spurious seeds, and asserting they were of the most genuine quality." (Thorburn, 1834)

Evidence suggests that some commercial seed dealers obtained seeds from the Shakers. And, in the early days, the Shakers sometimes supplemented their stocks with seed from "the World" By 1819, however, a covenant among the societies was signed that allowed only intervillage purchase, so that quality could be maintained. The quality of their seed was an issue that transcended marketing or profit making:

"We, the understated, having for sometime past felt a concern, lest there should come loss upon the joint interest, and dishonor upon the gospel, by purchasing seed of the world, and mixing them with ours for sale; and having duly considered the matter, we are confident that it is best to leave off the practice, and we do hereby covenant and agree that we will not, hereafter, put up, or sell, any seeds to the world which are not raised among believers (except melon seeds). (Sommers, 1972)

The Shakers are thought to have developed the innovation of packaging seeds for sale in small paper packets. This invention is attributed to James and Josiah Holmes, of Cumberland Co., Maine (Sommer, 1972). Before this time, seeds were generally sold in bulk in cloth sacks. Early seed packets were plain brown paper with only the variety name, the society of origin, and sometimes the gardener's name or initials printed on the front (Sommer, 1972). The first packets were cut and glued by hand in eight sizes. The seed packet sizes were referred to in New Lebanon Shaker journals by their use: Pound-bag size, bean size, beet size, onion size, cucumber size, cucumber long size, radish size, and lettuce size (Andrews and Andrews, 1974). By 1810, cutting and printing machines were developed to speed this process (Andrews, 1933). Packets were boxed in wooden display boxes (Fig. 2) and were marketed widely after 1810. The options for marketing this and other products were limited at that time. Some sales were made by mail-order, but most of the Shaker goods, including seeds, were sold by Shaker peddlers, who established routes throughout the northeastern United States. Wagons were packed with boxes of seeds, as well as herbs and herbal medicines, preserves, dried apples, brooms, cloth, wooden chairs, and many other items. Goods were sold door-to-door, village-tovillage, or provided to shopkeepers on consignment. It was by bringing their goods to rural communities that the Shakers were able to dominate the seed market in the United States for the first half of the 19th century. This marketing strategy worked well for the Shakers, and was continued by some societies into the late 1800 s.

The Shaker Seed Box became a fixture in many general stores across the eastern United States. A typical seed box held about 200 packets, selling for $5 \phi$ to $6 \phi$ each. The price for a box varied from $\$ 5$ to $\$ 12$. Arrangements were made with the storekeeper for a 
one-third commission, and the peddler would return the following winter to retrieve the wooden boxes, which were washed and repacked for the next season. The seed boxes distributed by the Shaker society of South Union, Ky., in 1885 were accompanied by the following statement:

"In presenting our Annual list of Choice Kitchen Garden Seeds it has been our earnest endeavor to make our assortment this year more attractive and valuable than ever. Our boxes sold on commission are adapted to the wants of country stores and the selection comprises the most popular standard varieties." (United Society of Shakers, 1885)

In addition to the seeds, this society offered asparagus roots, seed potatoes, sweetpotato slips, onion sets, and cabbage and tomato plants.

As their seed business grew, the Shaker societies found themselves faced with the marketing challenges of an expanding industry. Seed production increased in all communities and peddlers were sent out over broader areas. By the $1820 \mathrm{~s}$, there are references in Shaker journals to disputes over sales territories. The societies attempted to divide up territories equitably and efforts were made not to intrude upon other society's trading areas. But these attempts were not always successful. Polite debate over territory boundaries is recorded in numerous correspondence among the communities:

“. . . But the towns of Portsmouth, Dover, Sommersworth, we have invariably considered as belonging to our districts and cannot feel right in giving up any part of, as our routes is very small comparatively speaking...." (Sommer, 1972).

Ten years later, the disagreement continued. The words became stronger. Writing to the Shaker community at Alfred, Maine, the Canterbury deacons stated (1838):

"We are unlike our brethren at Alfred who have a great unbounded territory North and east of which no one holds a right or privilege and a means of extending the same especially since the grant from Gloucester. Just compare the extent of your district with ours and upon mature deliberation we think you will readily concede that we are asking, no more of you than you would ask of us were you placed in our circumstances." (Sommer, 1972)

By the 1830 s and 1840 s, competition with "the World" became an issue as well,

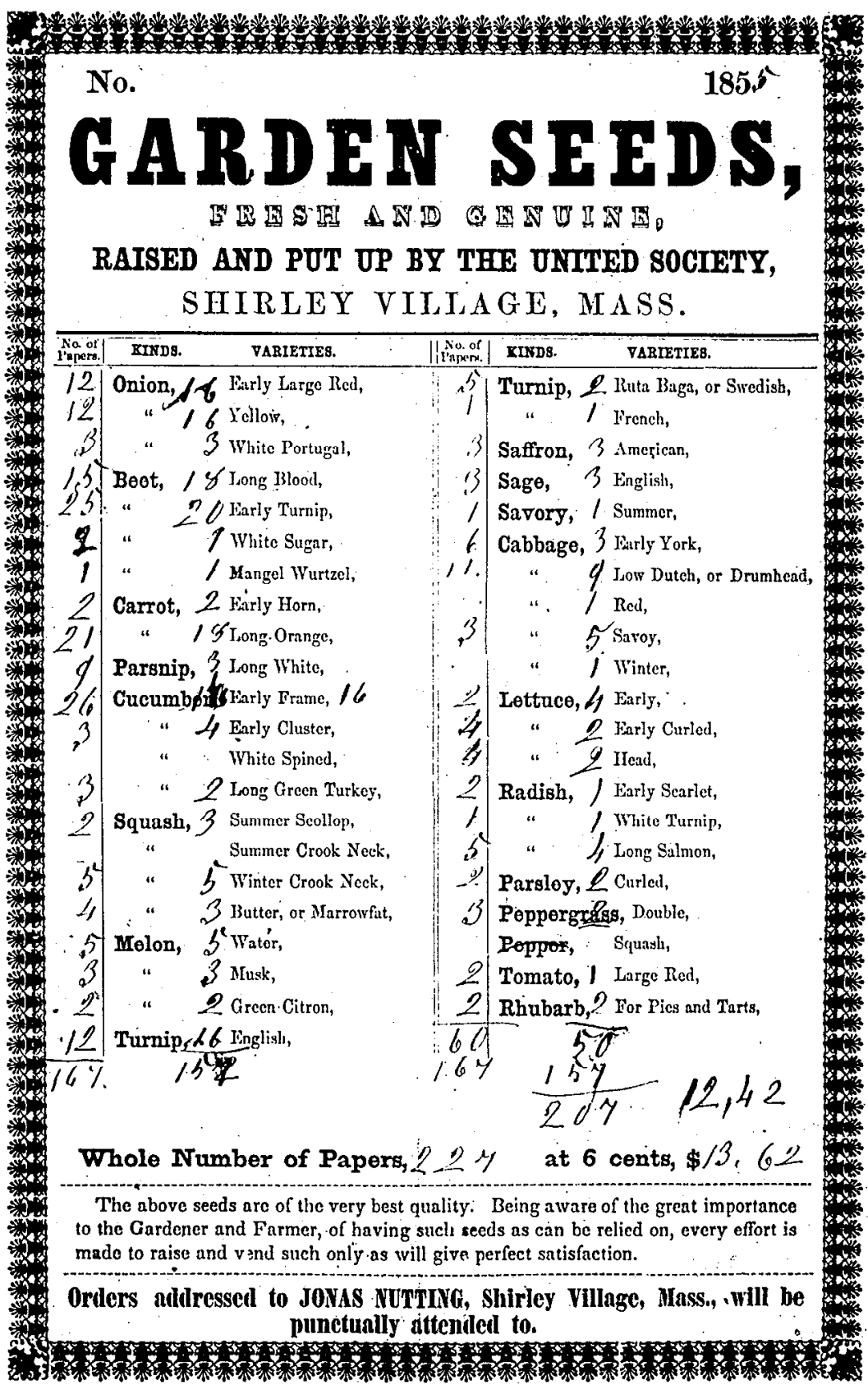

with a number of commercial seed businesses becoming established during this period. The advent of improved transportation and mail Fig. 5. Garden seed sales lists from the Shirley, Mass., Shaker colony, 1855 (WRHS Collection). 


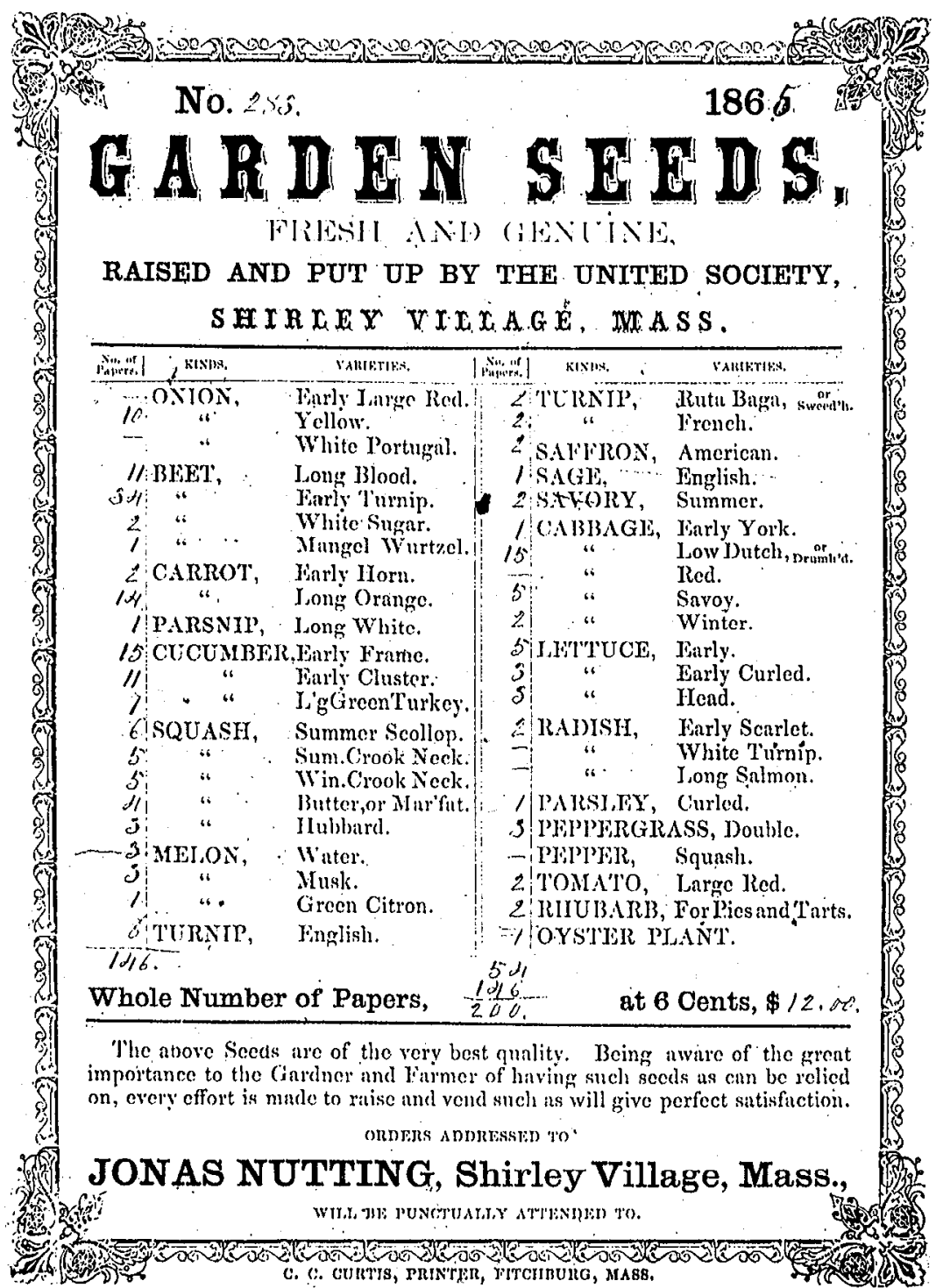

Fig. 6. Garden seed sales lists from the Shirley, Mass., Shaker colony, 1865 (WRHS Collection). ing tactic until the late 1850 s. They maintained that the quality of their seed was its own advertisement:

\footnotetext{
"We can bear the sway in Market if we are truly punctual to keep the quality of our seed good. Others may get them up in more nicer style and with finer colors, etc. than we deem it proper to do; but we can compete with them in the goodness and purity of the seed..." (Buckingham, 1848)
}

One Shaker response to commercial competition was the publication of a garden manual, which was displayed with the seed packets. The first of these was a combination catalog and gardener's manual written in 1836 by Charles Crossman, the New Lebanon garden deacon. Selling for $4 \phi$ to $6 \phi$, the garden manual set out

"to enable our trading customers... to obtain some practical information rela- tive to the raising and management of those valuable kitchen vegetables which are considered the most useful and important in a family." (Crossman, 1835)

Sixteen thousand manuals were printed in that first year.

With each new catalog, the Shakers added varieties to their seed lists. A series of seed lists from the Shirley, Mass., colony (Western Reserve Historical Society Collection) documents the expansion of offerings that occurred over the 19th century (Figs. 3-6). Shaker seed lists grew from 10 to 20 varieties in the early years, to catalogs offering more than 150 varieties offered by The Shaker Seed Company of New Lebanon in 1890. D.C. Brainard, garden Deacon at New Lebanon, writes in his 1873 catalog:

\footnotetext{
"We spare no pains or expense in procuring and testing every new variety brought to notice, and such as possess any real merits we recommend, but shall be slow to notice anything, the name of which constitutes its only value."
}

An example of their caution is the tomato. Introduced as an ornamental to Europeans from its native South America, the tomato was thought to be inedible during the 18th and early 19th centuries. First listed in Shaker seed catalogs in 1835, it was described as a "harmless, very delicious, wholesome and cheap vegetable." In 1843, catalogs were still cautiously referring to the tomato as "a healthy vegetable... though generally not very palatable at first.. .a great favorite once we become accustomed to it" (Sommer, 1972). By 1873 (Fig. 5), the Shaker Seed Company offered eight varieties of tomato (See Fig. 7), along with seven of turnip, six of lettuce, nine each of squash and radish, 11 of cabbage, 16 of peas, 15 of beans, plus 13 other types of vegetables, all with at least two varieties listed (Andrews and Andrews, 1974).

Throughout the 19th century, the Shakers maintained that the quality and variety of their product and the integrity of their business dealings would allow them to continue to compete successfully in the seed industry. How successful the Shaker seed industries were is difficult to determine. The scattered and incomplete records that are available can only give a general notion of the volume of sales. The Shaker Seed Company at New Lebanon was one of the longest-lived seed producers, and perhaps the most profitable. Packet production records give an indication of the volume of sales that this community conducted. Between 1846 and 1870, packet production at New Lebanon averaged 111,000 packets per year (Andrews and 
Andrews, 1974). Seed sales income is available for several years. The most profitable years occurred during the 1830s through the 1850 s. By mid-century, competition from commercial seed companies began to have a significant impact on the Shakers' business. In addition, the Civil War disrupted many of the societies' enterprises, and adversely affected sales of all their products, including seeds. After the war, the seed sales of a number of societies continued to decline. By the $1880 \mathrm{~s}$, most of the 15 Shaker seed enterprises were ended (Beale and Boswell, 1991). Those at Mount Lebanon, formerly New Lebanon (this community changed its name in 1861; Sommer, 1972) and Enfield and Canterbury, N.H., continued into the 1890s. The Enfield society offered seeds for sale until 1919. The demise of the Shaker Seed industry is summarized well by Elder Henry Blinn:

"The Business was very prosperous till many other parties entered the field. Those by ornamental printing on the seed bags, by extended advertising and the offering of premiums, soon captivated the dealersand consumers and left the Believers with their simple unattractive showbills and seed bugs quite a long distance in the rear and finally obliged them to withdraw from the market." (Beale and Boswell, 1991)

\section{Conclusions}

There was a time in the early to mid 1800 s when Shaker peddlers, visiting communities across the northeastern and midwestern United States, were the only source for garden seeds and many other products. Shaker seeds and goods were sought after; their quality guaranteed. As the commercial seed industry grew, the quality of Shaker seeds provided a standard by which many rural gardeners judged the newly available commercial seeds. Early commercial seed dealers were forced to consider this as they purchased seed from suppliers. The quality issue continued to be a problem late in the 19th century, as described by J.J.H. Gregory (1879):

"As the seed business is conducted in this country, the seed grower and seed dealer are usually distinct, but few dealers growing the seed they sell. One defect of this is, that there are too many chances against the farmer's getting good seed. The dealer who does not raise his seed, does not how anything about it personally...they pass through several bands and, of course, the more bands they pass through, the more danger there is that the seed will not be good."

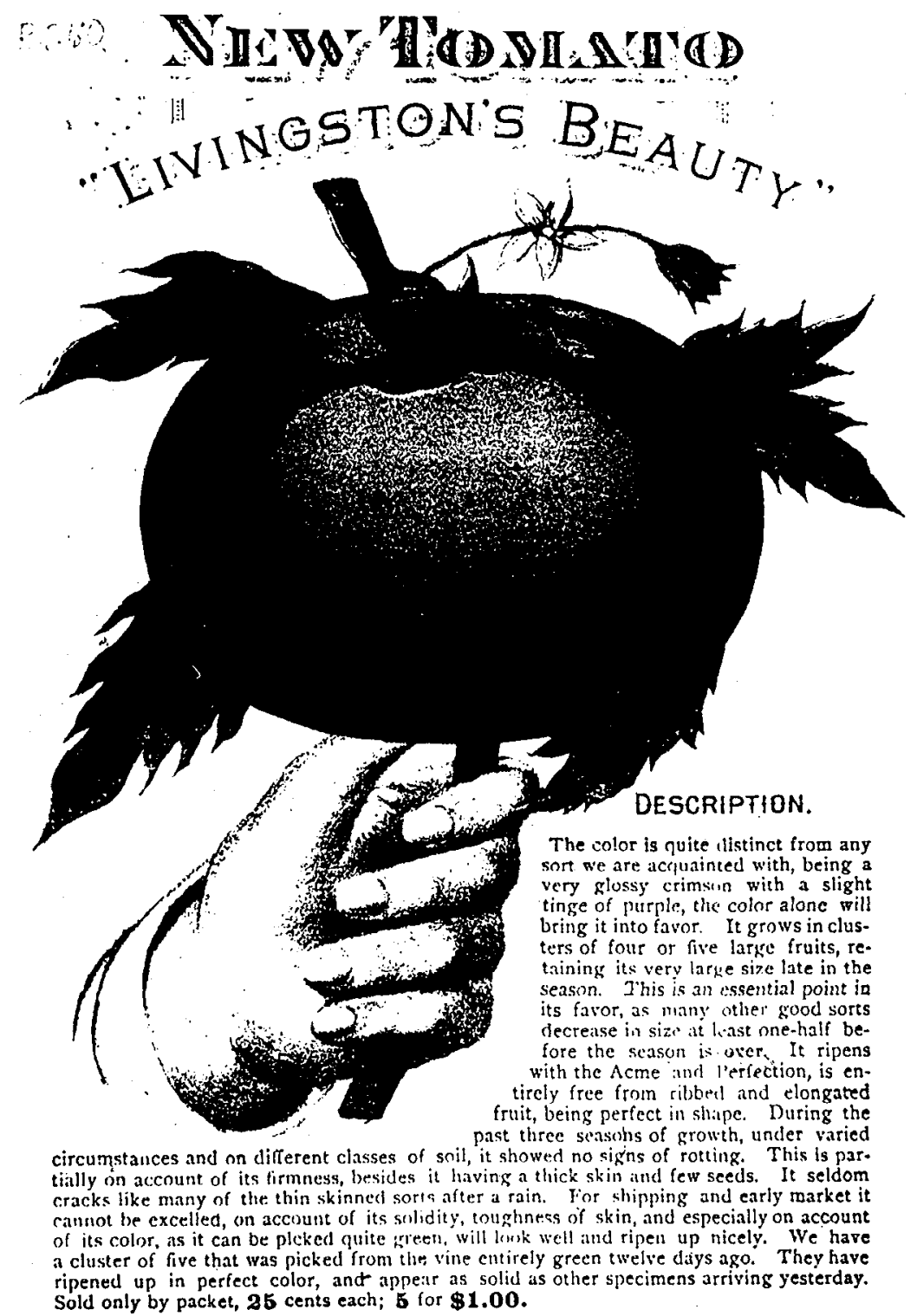

SHAKER SEED COMPANY. Wholesale und Retail Dealers in Garden Seeds. MT. IEEAANON, N: $T$

In spite of this handicap, competition from commercial seed dealers forced many Shaker seed growers out of business. The opening up of rural markets to urban producers and manufacturers during the latter half of the 19th century affected all Shaker industries. As the nation became more settled, transportation better-established, and the population more sophisticated, Shaker products, as well as their doctrine, became less and less compatible with the times. Those societies that were willing to adapt survived the longest, but the Shaker doctrine involving strict social and interpersonal structure ultimately caused the decline and abandonment of most Shaker communities. Only a few Shaker Elders remain alive today. Two societies continue in existence: Those at Canterbury, N.H., and Sabbathday Lake, Maine. A number of the societies have been incorpo-
Fig. 7. A Shaker advertisement for the Livingston tomato from some time in the 1860 s or 1870 s, exact date unknown (WRHS Collection). 
rated as museums (see Fig. 1). and thus can provide the public with an understanding of this unique culture and its role in the development of rural America.

\section{References}

Andrews, E.D. 1933. The New York Shakers and their industries. New York State Museum, Albany. Circ. 2

Andrews, E.D. and F. Andrews. 1974. Work and worship: The economic order of the Shakers. New York Graphic Soc. Greenwich, Conn.

Beale, G. and M.R. Boswell. 1991. The earth shall blossom. The Countryman Press, Woodstock, Vt.

Buckingham, D.A. 1848-1854. A journal or a daily account of passing events, kept for the benefit of the church, first order. January 1, 1848-May, 1854. Watervliet, N.Y. WRHS Reel 44 VB 280.

Crossman, C.F., 1835. The gardener's manual: Containing plain and practical directions for the cultivation and management of some of the most useful culinary vegetables: To which is prefixed a catalog of the various kinds of garden seeds raised in the United Society at Enfield, Conn., with a few general remarks on the management of a kitchen garden. Albany, N.Y. WRHS Microfiche Collection 370 , N.P.

Gregory, J.J.H. 1879. Culture of vegetable seeds. Rpt. of the Connecticut Board of Agriculture and Experiment Station, 1878-79. Case, Lockwood and Brainard Co, Hartford.

Hawthorn, L.R. and L.H. Pollard. 1954. Vegetable and flower seed production. The Blakiston Co., New York.
Hedrick, U.P. 1933. A history of agriculture in the State of New York. New York State Agr. Soc., Albany.

Hedrick, U.P. 1950. A history of horticulture in America to 1860. Oxford Univ. Press, New York.

Landreth, B. 1923. Early days in the seed industry. Seed World 14(12):13-14.

Melcher, M.F. 1941. The Shaker adventure. Princeton Univ. Press, Princeton, N.J.

Pieters, A.]. 1900. Seed selling, seed growing, and seed testing. 1899 Yrbk. of the USDA, U.S. Government Printing Office, Washington, D.C.

Sommer, M.F. 1972. The Shaker garden seed industry. The Shaker Museum Foundation, Old Chatham, N.Y.

Thorburn, G. 1834. Forty years residence in America. Russell, Odiorne, and Metcalf, Boston.

United Society of Shakers, Shirley, Mass. 1824, 1832, 1855, 1865. Seed lists. Western Reserve Historical Society Shaker collection on microfilm at the Wisconsin State Historical Society, Call\#B1-B420.

United Society of Shakers. 2843. A Shaker garden manual. [Reprintedin 1980 by Applewood Books, Boston.]

United Society of Shakers. 1885. Farm annual of the United Society of Shakers. South Union, Ky.

WRHS Collection. n.d. A brief history of the raising of garden seeds among the believers, \&c. WRHS Collection, Microfilm Reel 44 VB279. 